\title{
PENINGKATAN PELAYANAN KA COMMUTER JABODETABEK
}

\author{
Ir. Tonny C.M Korah, M.Si \\ Dosen STTD \\ Jl. Raya Setu Km. 3,5 Cibuntu, \\ Cibitung, Bekasi 17520 \\ Telp./fax. 0218254640 \\ e-mail tonickorah@yahoo.com \\ info.p3m.sttd@gmail.com
}

\author{
A. Ubaini Rasyid, S.SOS., MM \\ Dosen STTD \\ Jl. Raya Setu Km. 3,5 Cibuntu, \\ Cibitung, Bekasi 17520 \\ Telp./fax. 0218254640
}

\author{
Ir. Djoko Septanto, MM. \\ Dosen STTD \\ Jl. Raya Setu Km. 3,5 Cibuntu, \\ Cibitung, Bekasi 17520 \\ Telp./fax. 0218254640
}

\author{
Drs. Hotland Silaban, M.Si. \\ Dosen Dosen STTD \\ Jl. Raya Setu Km. 3,5 Cibuntu, \\ Cibitung, Bekasi 17520 \\ Telp./fax. 0218254640
}

\begin{abstract}
Improved commuter rail services jabodetabek when jakarta city station was flooded.The study, optimization of services perrgerakan commuter rail line bead on sat station jakarta city stagnant water where the setting telecommunications signal is disturbed then the end station jakarta city was transferred to the station jayakarta and station intercity long distance transferred from Gambir station to station Manggarai and Jatinegara, was operating the commuter line cross-Manggarai -jakarta town stopped at the station jayakarta used only commuter train line that runs in the same direction using one rail commuter train and the next line waiting at Gambir station and that's simulations are used alternately so that the commuter train service line may be optimized with very strict control and always be alert and cautious in its implementation.
\end{abstract}

Keywords: Improved, Competencies, Implementation, Portion Practice and Theory, Description, Coefficient of Determination

\begin{abstract}
ABSTRAKSI
Peningkatan pelayanan kereta api komuter jabodetabek pada saat stasiun jakarta kota tergenang banjir. optimalisasi pelayanan perrgerakan kereta api komuter line jabodetabek pada sat stasiun jakarta kota tergenang air dimana pengaturan sinyal telekomunikasi terganggu maka stasiun akhir jakarta kota dipindahkan ke stasiun jayakarta dan stasiun antarkota jarak jauh dipindahkan dari stasiun gambir ke stasiun manggarai dan jatinegara,sedang operasi komuter line lintas manggarai -jakarta kota yang berhenti di stasiun jayakarta hanya digunakan kereta komuter line yang berjalan searah dengan menggunakan sepur salah dan kereta api komuter line berikutnya menunggu di stasiun gambir dan hal itulah simulasi yang digunakan secara bergantian sehingga pelayanan kereta api komuter line dapat berjalan secara optimal dengan pengawasan yang sangat ketat dan selalu waspada dan berhati hati dalam pelaksanaannya.
\end{abstract}

Kata Kunci : Peningkatan, Kompetensi, Implementasi, Bagian Praktek dan Teori, Deskripsi, Koefisien 


\section{A. LATAR BELAKANG}

Seperti kita ketahui bersama bahwa kereta api komuter lintas jabodetabek merupka angkutan umum berbasis rel yang merupakan alternatip angkutan umum selain angkutan jalan yang banyak disukai oleh masyarakat jakarta dan sekitarnya seperti bogor bekasi tangerang dan depok karena disamping cukup nyaman angkutan ini mempunyai waktu tempuh yang relatif cepat dan bebas dari kemacetan seperti angkutan jalan ,Sedang ciri ciri angkutan umum berbasus rel ini mempunyai kelebihan sebagai berikut :

1. Pelayanan angkutan umum kereta api komuter line dapat mengangkut kapasitas lebih besar,waktu tempuh relatif cepat dan tarip yang terjangkau.

2. Pelayanan pada simpul juga cukup baik karena menyediakan fasilitas park and ride yang cukup memadai.

3. Mudah dicapai karena aksesibiliti yang baik karena dtunjang oleh jalan arteri primer baik didalam kota maupun diluar kota.

Namun demikian angkutan umum berbasis rel yang tersedia di stasiun lokasi yang diteliti juga masih mempuyi kelemahan yakni ruang peron dan ruang keluar dan masuk dari dan ke emplasemen yang belum memadai serta akses keluar masuk stasiun yang masih belum terakses dengan baik karena kurang taatnya angkutan umum jalan seperti yang terlihat di sta. Bekasi.yang berani menaikan dan menurunkan penumpang serta menunggu penumpang dipintu masuk dan bahkan menunggu penumpang di dalam stasiun sehingga pintu masuk dan keluar stasiun menjadi terganggu.

\section{B. IDENTIFIKASI MASALAH}

Dari latar belakang tersebut diatas teridentifikasi permasalahan sbagai berikut :

1. Pelayanan penumpang di sta.awal , antara dan tujuan seperti sta bekasi,manggarai,jakarta/kota belum memuaskan masyarakat pengguna jasa

2. Pada saat jam sibuk pelayanan peron belum memuaskan dan ada stasiun antara panjang peron tidak sesuai dengan rangkaian kereta 
3. Pelayanan perpindahan kereta antar jalur pada beberapa emplasement stasiun sangat berbahaya bagi penumpang

4. Terbatasnya jalur pada emplasemen stasiun mengakibatkan bertambahnya waktu tempuh

5. Ruang untuk penumpang keluar dan masuk serta transit

Masih belum tertata

\section{BATASAN MASALAH}

Dikarenakan terbatasnya waktu ,sumber daya manusia dan anggaran yang tersedia maka Penelitian ini dilakukan terbatas pada pelayanan KML di stasiun awal, antara dan tujuan seperti bekasi,manggarai,jakarta/kota terkait kinerja di dalam dan di luar emplasement, kinerja akses dari dan ke stasiun serta kinerja jalur.

\section{RUMUSAN MASALAH}

Dari batasan masalah yang telah dijelaskan tersebut diatas maka untuk mempermudah penyusunan pelaksanaa penelitian ini disusun perumusan masalah agar nantinya dalam analisa dan pembahasan akan didapat hasil yang optimal yakni sebagai berikut :

1. Upaya upaya apa yang harus dilakukan agar pelayanan peron dapat memuaskan pelanggan KML?

2. Upaya upaya apa yang harus dilakukan agar jumlah jalur dapat melayani operasi ka KML dengan zero delay dan sesesuai dengan perencanaan GAPEKA ?

3. Upaya upaya apa yang harus dilakukan agar perpindahan orang di emplasement tidak membahayakan penumpang itu sendiri?

\section{E. TUJUAN}

Tujuan dari penelitian ini adalah untuk meningkatan kinerja pelayanan KML khususnya di stasiun bekasi , manggarai dan jakarta /kota.Yang terkait dengan pelayanan peron ,jalur kereta api di emplasemen,ruang masuk dan keluar emplasemen serta akses keluar masuk stasiun . 


\section{F. URGENSI PENELITIAN}

Sebagai bahan masukan dan pertimbangan bagi instansi terkait dalam rangka mempercepat peningkatan kinerja pelayanan kereta api komuter line khususnya di stasiun bekasi ,stasiun manggarai dan stasiun jakarta kota.

\section{G. SISTEMATIKA LAPORAN}

Penyusunan penelitian ini dibahas dalam 5 ( lima ) bab ,dimana antara bab satu dengan bab yang lain saling terkait sehingga pembaca akan dengan mudah mengerti mengenai apa yang dimaksud dan tujuan dari penelitian ini.oleh karena itu sistematika penulisan ini dapat dijelaskan sebagai berikut

\section{METODE PENELITIAN}

Penelitian dilakukan diwilayah kerja Daerah operasi I yakni di stasiun pemberangkatan,tujuan dan antara seperti stasiun bekasi ,stasiun manggarai dan stasiun jakarta kota yang terkait dengan peron,jalur pada emplasemen,akses keluar masuk dari emplasemen dan akses masuk keluar stasiun.

Sedang langkah langkah penelitian dimulai dari :

1. identifikasi masalah yang ada pada lokasi penelitian selanjutnya agar dalam pembahasan menjadi fokus dan terarah permasalahan dibatasi sesuai dengan yang akan diteliti dan selanjutnya untuk mempermudah penyelesaian dalam penelitian maka permasalahan yang telah dibatasi tersebut dirumuskan .

2. pengumpulan data meliputi pengumpulan data primer yang didapat dari hasil survey serta data sekunder yang didapat dari instasi terkait serta penelitian yang telah dilakukan terdahulu serta referesi lain baik dari media cetak maupun elektronik

3. analisis dan pembahasan menggunakan analisa deskriptif chi kuadrat dua sampel dengan variabel mandiri yang diamati yaitu tingkat pelayanan dan 
analisa hubungan melalui koofisien korelasi gamma ( $\mathrm{y}$ ) dengan variabel teramati adalah tingkat kepuasan dan tingkat pendidikan . 


\section{A. POLA PIKIR}

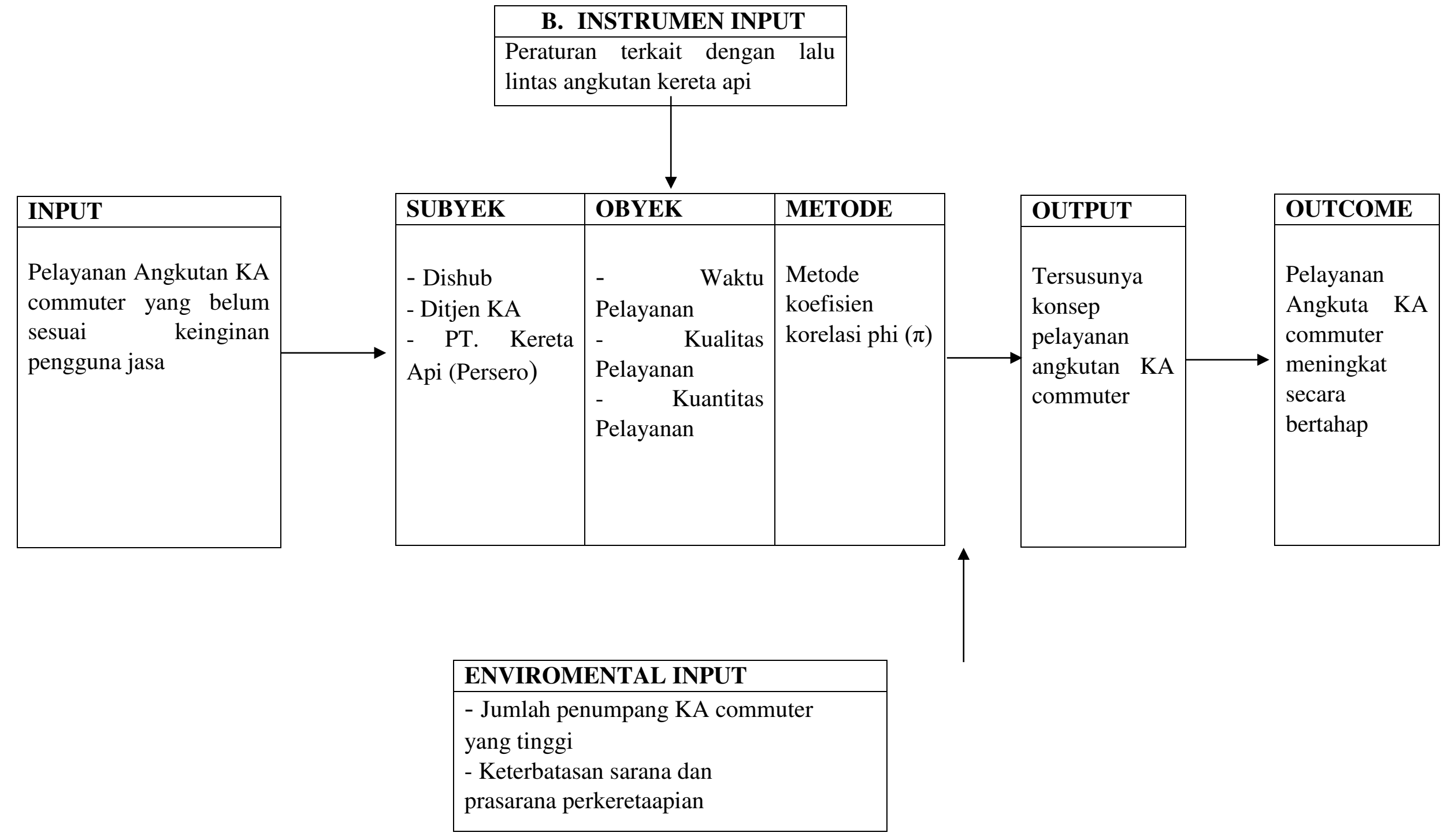




\section{ALUR PIKIR PENELITIAN}

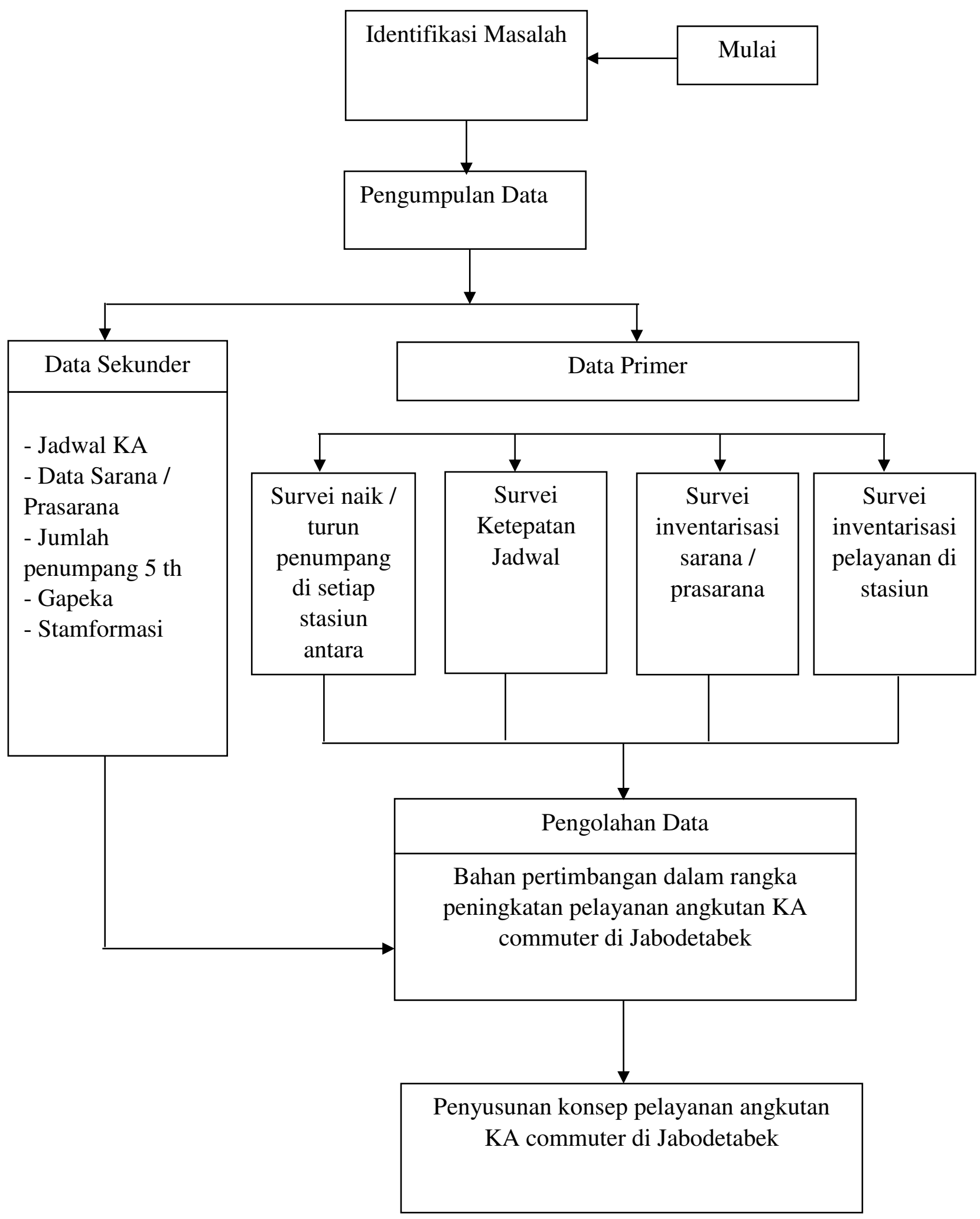




\section{METODE ANALISA}

Analisa yang digunakan dalam pembahasan penyelesaian penelitian ini adalah :

1. Analisa deskriptif dengan variabel mandiri yang diamati

Seperti tingkat pelayanan melalui :

a. Analisa kinerja jalur menghitung utilisasasi tingkat penggunaan jalur lintas manggarai -bekasi,manggarai -jakarta kota dan jatinegara - jakarta kota

b. Analisa kinerja pelayanan peron Menghitung utilisasasi fungsi peron yang berkaitan dengan jumlah penumpang naik dan turun pada sat jam sibuk

c. Analisa kinerja pelayanan jalur di emplasemen

Menghitung utilisasasi ketersediaan jalur untuk

kelancaran operasi angkutan kereta api komuter line dan akses perpindahan penumpang di emplasemen

d. Analisa kinerja ruang untuk keluar masuk penumpang dari dalam emplasemen Menghitung utilasasi ruang yang tersedia untuk keluar masuk emplasemen dan stasiun

e. Analisa kinerja ruang untuk keluar dan masuk stasiun

Yaitu melihat dengan cermat pola pergerakan yang terjadi terkait dengan kepadatan jalan yang tersedia untuk masuk dan keluar dari stasiun serta ketersediaan pengaturan parkir di setasiun

2. Analisa hubungan melalui koofisien korelasi gamma

( $\mathrm{y}$ ) dengan variabel bebas teramati yaitu tingkat pendidikan dan tingkat kepuasan.

\section{E. HIPOTESIS}

Pengujian hipotesis dalam penelitian ini digunakan Hipotesis deskriptif dengan menganmati kekuatan variabel mandiri dengan tidak mempersoalkan perbandingan dan hubungan dari variabel melalui rumusan masalah sebagai berikut :

a. Berapakah tingkat pelayanan yang dihasilkan oleh kinerja peron,jalur di emplasemen dan ruang masuk serta keluar stasiun ? 
Dari rumusan masalah tersebut dituangkan dalam rumusan hipotesis deskriptifnya adalah :

b. Tingkat pelayanan yang dihasilkan oleh kinerja jalur aa $\%$, kinerja peron telah mencapai xx \%,kinerja jalur di emplasemen mencapai yy \% dan kierja masuk keluar stasiun mencapai zz \%

Selain hipotesis deskriptif peneliti juga mencoba menilai kekuatan hubungan antar variabel yang diamati seperti kekuatan hubungan antara tingkat pendidikan dengan tingkat kepuasan konsumen dengan menggunakan analisa hubungan melalui koofisien korelasi gamma ( $\mathrm{\gamma}$ )

\section{ANALISA DAN PEMBAHASAN}

1. Analisa kinerja pelayanan jalur

a. Lintas bekasi - jatinegara

Jalur Lintas bekasi ke jatinegara tersedia dua sepur untuk pelayanan lalu lintas kereta api jarak jauh,jarak dekat dan kereta api komuter jabodetabek.Jumlah pergerakan kereta api untuk lintas jarak jauh dalam satu hari operasi ada 66 pergerakan,sedang untuk kereta api jarak pendek 2 pergerakan sementara untuk kereta api komuterline jabodetabek terdapat 198 pergerakan .Untuk waktu satu jam sibuk satu sepur lintas bekasi jatinegara pada hari senen jam $07.00 \mathrm{~s} / \mathrm{d}$ jam 08.00 dihitung per penggal jalan kereta api yakni antaa stasiun bekasi - stasiun kranji terdapat 5 kereta jarak jauh dan 8 kereta komuter line dengan asumsi kecepatan kereta api $60 \mathrm{~km} / \mathrm{jam}$ pelayanan sintellis elektonik maka kinerja jalur adalah 54,16\%.Sedang pola operasi yang tersedia adalah ka komuter line apabila jadwal pada gapeka berimpit dengan KA jarak jauh maka KA komuter line harus berhenti menunggu untuk didahului oleh ka jarak jauh di stasiun bekasi . sedang apabila berimpit pada penggal jalur antara stasiun kranji stasiun cakung maka KA komuter line akan berhenti untuk didahului di stasiun cakung, sedang untuk menuju stasiun jatinegara KA komuter line akan didahului dan bersimpang di stasiun jatinegara. 
Gambar Jalur KA lintas bekasi - jatinegara untuk KA jarak jauh dan komuter
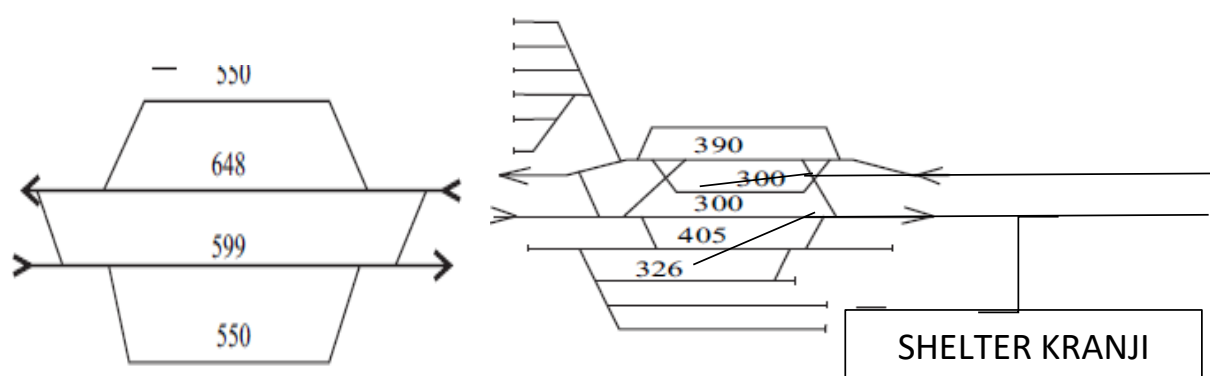

STASIUN CAKUNG

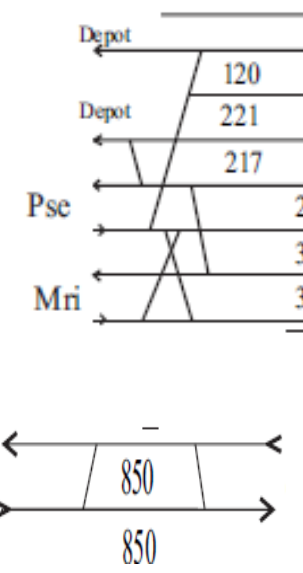




\section{KESIMPULAN DAN SARAN}

\section{KESIMPULAN}

Dari hasil analisa dan pembahasan mengenai kinerja pelayanan angkutan komuter jabodetabek yang terkait dengan pelayanan emplasemen dan stasiun yang khusunya di stasiun jakarta kota -manggarai dan bekasi dapat ditarik kesimpulan sebagi berikut :

\section{Stasiun bekasi}

a. Kinerja jalur antar stasiun

Kinerja jalur antar stasiun untuk lintas bekasi- jatinegara pada pagi hari antara jam 07.00 sampai dengan jam 08.00 adalah 54,16 \% hal ini sama dengan waktu sore hari dimana pada waktu pagi dan sore hari adalah waktu berangkat dan pulang kerja sehingga pada waktu waktu tersebut sangat padat oleh penumpang yang menggunakan jasa kereta api komuter line.

b. Kinerja emplasemen

Kinerja peron pada pagi hari adalah untuk penumpang menunggu di peron sepur tiga adalah 55,76\% dan penumpang turun sore hari pada peron sepur tiga adalah $61,97 \%$

c. Kinerja stasiun

Kinerja stasiun yang terdiri dari kinerja antrean ticketing,kinerja parkir dan kinerja akses keluar masuk stasiun bekasi sangat buruk hal ini terlihat dari panjang antrean tiket yang hampr keluar pintu masuk stasiun,ruang parkir yang kurang luas dan banyaknya kendaraan menaikan dan menurunkan penumpang di mulut pintu setasiun, sehingga kinerja fasilitas stasiun bekasi > $100 \%$.

2. Stasiun Manggarai

a. Kinerja jalur antar stasiun

Kinerja jalur antar stasiun untuk lintas jatinegara - manggarai pada pagi hari antara jam 07.00 sampai dengan jam 08.00 adalah 45,83\% dan untuk lintas bogor - manggarai adalah 46,80 \% , hal ini sama dengan waktu sore hari dimana pada waktu pagi dan sore hari adalah waktu berangkat dan pulang kerja sehingga pada waktu waktu tersebut sangat dipadati oleh penumpang yang menggunakan jasa kereta api komuter line.

b.Kinerja emplasemen 
Kinerja peron pada pagi hari adalah untuk penumpang menunggu di peron sepur enam tujuan bogor dan sepur tiga tujuan jakarta kota rata rata adalah adalah 49,82 \% dan penumpang naik pada sore hari di peron sepur empat tujuan bekasi dan peron 6 tujuan bogor rata rata adalah sekitar 71,65\% .

c. Kinerja stasiun

Kinerja stasiun yang terdiri dari kinerja antrean ticketing terlihat cukup rapi dan baik sedang kinerja akses keluar masuk penumpang stasiun manggarai juga terlihat cukup baik yakni rata rata adalah sekitar $82 \%$ pada pagi dan sore hari,sedang untuk kinerja parkir tidak dapat dinilai karena pada stasiun manggarai tidak terdapat ruang parkir.

3. Stasiun jakarta kota

a. Kinerja jalur antar stasiun

Kinerja jalur antar stasiun untuk lintas jatinegara - senen pada pagi hari antara jam 07.00 sampai dengan jam 08.00 adalah 36,67\% dan untuk lintas senen Jakarta kota adalah $32 \%$, hal ini sama dengan waktu sore hari dimana pada waktu pagi dan sore hari adalah waktu berangkat dan pulang kerja sehingga pada waktu waktu tersebut sangat padat oleh penumpang yang menggunakan jasa kereta api komuter line.

b.Kinerja emplasemen

Kinerja peron pada pagi hari adalah untuk penumpang menunggu di peron sepur sepuluh dan sebelas untuk tujuan bogo dan bekasi rata rata adalah sekitar 29,72 \% dan penumpang naik pada sore hari pada peron sepur sepuluh dan sepur sebelas untuk tujuan bogor dan bekasi rata rata adalah sekitar $75,97 \%$

c. Kinerja stasiun

Kinerja stasiun yang terdiri dari kinerja antrean ticketing,kinerja parkir dan kinerja akses keluar masuk stasiun Jakarta kota sebelah selatan sangat buruk hal ini terlihat dari panjang antrean tiket yang hampr keluar pintu masuk stasiun Jakarta kota dengan kinerja $>! 00 \%$,sedang untuk kinerja parkir dan akses keluar masuk setasiun sudah cukup memadai yakni rata rata sekitar $75,64 \%$. 


\section{A. SARAN}

Dari kesimpulan diatas dapat dijelaskan bahwa ada beberapa failitas seperti peon ,akses perpindaha penumpang didalam emplasemen ,ruang masuk dan keluar emplasemen serta fasilitas parkir serta akses masuk keluar stasiun yang perlu ditingkatkan seperti pada stasiun tersebut dibawah ini

1. Stasiun bekasi

a.Kinerja jalur antar stasiun

Peningkatan kualitas pelayanan ka komuter lintas jabodetabek melalui penambahan jalur menjadi 4 sepur untuk lintas cikarang - bekasi - jakarta kota

b.Kinerja emplasemen

Perluasan ruang dan masuk keluar emplasemen,Penambahan jalur di emplasemen untuk transit,Pembuatan akses yang tidak sebidang didalam emplasemen.

c. Kinerja stasiun

Penambahan luas untuk ruang penjualan loket,Penambahan luas untuk ruang parkir,Penataan parkir sesuai ,Melarang dengan keras angkutan umum jalan masuk keruang parkir stasiun serta menaikan dan menurunkan dan menunggu penumpang didepan pintu keluar dan masuk stasiun,Pengaturan akses keluar dan masuk stasiun dan melarang pedagang kaki lima berjualan di pentu masuk dan trotoar disekitar stasiun

2.Stasiun Manggarai

a. Kinerja jalur antar stasiun

Diusulkan 4 sepur untuk lintas manggarai - jakarta kota dan 4 sepur untuk lintas manggarai - sta. Senen - jatinegara akses sta. Tanah abang serta 3 sepur untuk lintas manggarai - bogor

b.Kinerja emplasemen

Perluasan ruang untuk masuk dan keluar emplasemenSehingga antrean tidak panjang, Penambahan jalur di emplasemen untuk transit sebanyak 3 sepur 
simpang ,Pembuatan akses yang tidak sebidang didalam emplasemensebanyak 5 akses koridor

c. Kinerja stasiun

Penambahan luas untuk ruang penjualan loketPenambahan luas untuk ruang parkirPenataan parkir,Melarang dengan keras angkutan umum jalan masuk keruang parkir stasiun serta menaikan dan menurunkan dan menunggu penumpang didepan pintu keluar dan masuk stasiun Pengaturan akses keluar dan masuk stasiun.

3. Stasiun jakarta kota

a. Kinerja jalur antar stasiun

Untuk lintas jakarta kota - manggarai diusulka 4 sepur,untuk maggarai bogor diusulkan menjadi 3 sepur sesuai prioritas pada waktu sibuk dan untuk jakarta kota - senen -jatinegara sampai dengan bekasi - cikarang juga menjadi 4 sepur.

b.Kinerja emplasemen

Perluasan ruang dan masuk keluar emplasemen,Penambahan jalur di emplasemen untuk transit,Pembuatan akses yang tidak sebidang didalam emplasemen.

c. Kinerja stasiun

Penambahan luas untuk ruang penjualan loketPenambahan luas untuk ruang parkirPenataan parkir,Melarang dengan keras angkutan umum jalan masuk keruang parkir stasiun serta menaikan dan menurunkan dan menunggu penumpang didepan pintu keluar dan masuk stasiunPengaturan akses keluar dan masuk stasiun.

\section{DAFTAR PUSTAKA}

A. Suharti erna Evaluasi pengoperasian rel listrik ( KRL) ekonomi AC pada PT KA komuter jabodetabek

B. Purwoko upaya meningkatkan peran kereta api jabodetabek sebagai angkutan perkotaan yang efektif 
C. Supriadi,uned

operasi kereta api 